more important than this, however, the shaping of a new society in India depends in large measure on the intelligent analysis of social trends and, in particular, on what Prof. Mukerji terms "culture-assimilation", and this is one of the more important tasks for the Indian sociologist to accomplish. Prof. Mukerji and his colleagues see themselves as members of a society attempting to avoid domination by both American and Russian culture and civilization. American sociology is sometimes presented to the Indian scholar as "a scientific discipline to save the world from Marxism"; but Dr. M. N. Srinivas roundly declares in his article on "Social Anthropology and Sociology" that, for all their claim to be "scientists', American sociologists implicitly, but none the less deeply, believe in the values of contemporary America. The Indian sociologist, therefore, appears to be embarking on an attempt to develop his own study in his own way, rejecting both the American and the Russian patterms. His colleagues throughout the Western world will watch his work with interest and sympathy.

\section{Japanese Researches in Biophysics}

THe Research Institute of Applied Electricity, Hokkaido University, Sapporo, Japan, has followed up its first monograph, entitled "Theory and Application of High Frequency Phenomena" (see Nature, 167,$102 ; 1951$ ), by a second interesting monograph on "Some Researches on Biophysics" (Monograph Series No. 2; pp. 69 ; August 1, 1951). This latter publication, which is edited by $Y$. Asami, contains six articles: the first two are concerned with the effects of radiation on proteins, the next two with the methods of excitation of and electrical conduction along nerves, and the remaining two with physiochemical problems. M. Wakabayashi and F. Kawamura describe what is probably the first reliable investigation of the effects of large doses $\left(10^{5}-10^{8} \mathrm{r}\right.$.) of X-rays on the serum proteins. The chemical changes produced were examined, and the results obtained were compared with the changes produced by ultra-violet radiation or by heating. The rapid vapour-pressure method of determination of the water content of easily purified proteins, devised by $\mathrm{K}$. Hirota and F. Kawamura, is the subject of the other article on proteins, and the results of the application of the method to gelatin and fresh muscles support Wakabayashi and Kawamura's work. The other articles deal with the following topics: the spike and dome potential observed in the oil/saline-water nerve model; study of the discharge pattern of Hering's sinus nerve and the excitation mode in the chemoreceptor's of the carotid body; polarographic measurements of oxygen concentration in vivo; and dielectric absorption and anomalous dispersion of polar solutions.

\section{Forest Taxation in New Zealand}

IN Information Series No. 11 of the New Zealand Forest Service (Wellington, 1950), Mr. M. B. Grainger discusses the question of forest taxation, a recurring problem which appears still to be far from settled, since opinions differ widely on what should be a fair burden to lay upon forests, the produce from which is essential to all types of the human race in one form or another, quite apart from industrial utilization. Private forests, especially commercially owned private forests, as apart from the Government forests, play an important part in the forest economy of New Zealand. As Mr. Grainger says, "The National Forest policy has always envisaged private forests playing a significant part in New Zealand's timber and wood economy and therefore the Forest Service has sought to encourage good standards of forest management". The methods of taxing forest land and forest operations have proved increasingly difficult during the past thirty years and have come in for a good deal of criticism, certain anomalies, not unknown in other countries, having become apparent. It must be obvious to all that a property like a forest cannot be looked at from the same point of view as a house or industrial buildings, or even a farm with its short-term growing crops, and so forth. The forests, even short-rotation crops of 15-20 years or so for firewood, paper pulp, etc., are not so easily assessed for taxation purposes. There is no doubt that excessive taxation based on inability to grasp the different growing conditions and the longevity of these conditions have been in the past, and are at the present day, a serious threat to the perpetuation of the forest in parts of the world where this maintenance is of the first importance to the population of the country concerned. Before he formed the opinion that contemporary tax practice in New Zealand is prejudicial to good forestry, Mr. Grainger visited a number of selected European countries. In this brochure taxation methods in Great Britain, Sweden, Finland, France and Norway are briefly dealt with, the various systems compared and then contrasted with those of New Zealand, and proposals made with reference to the latter country.

\section{Planets and Sunspots}

THE third part of K. G. Meldahl's paper on "Tidal Forces in the Sun's Corona due to Planets", which has recently been published (pp. 14 of text, and pp. 16 of illustrations. Copenhagen: Berlingske Forlag, 1952), carries on the work of the other two parts, published in 1938 and 1949 respectively (see Nature, 144,726 (1939) and 165, 301 (1950); and also 166, 1058 (1950) ). In Part 2 it was shown that a period of 308.52 years has a powerful influence on the vertical tides, confirmatory evidence of which was found in the observations of auroras and sunspots. It was also pointed out that the partial force periods of the sun include one of $22 \cdot 38$ years, which approximates to Hale's estimated period for the changing polarity of the spots, and in Part 1 it was suggested that the disturbance which caused the spots moved along the meridian plane or nearly so. It remains to be seen whether Hale's observations will confirm Meldahl's views. While Part 3 repeats some of the results previously obtained, it also contains many new features and includes a separate portion with sixteen illustrations. These show that there is a preponderance of meridional forces pointing towards the equator, with maxima at about $45^{\circ}$ latitude, and it is suggested that there may be corresponding currents in the coronal gases, such currents being subject to similar centrifugal forces in addition to the ordinary forces due to the sun's rotation. A number of photographs of solar eclipses are reproduced for 1860-1901, and these show the diamond shapes in the corona with four cusps at $45^{\circ}$ latitude, thus corroborating the meridional forces already referred to. Certain hydrodynamic phenomena-in particular the case of a fluid surrounding a rotating sphere-are outlined in two illustrations, and it is found that a number of configurations resembling those found on the sun are in evidence in the experiments. Disappointed with the lack of satisfactory explanations of currents 